\title{
Value Creation in Research Based Production Systems: An Empirical Study
}

\author{
Maria Rosaria Marcone, Domenico Carminucci \\ Polytechnic University of Marche, Ancona, Italy
}

\begin{abstract}
The current paper investigates empirically the relation between relatively radical changes (radical for medium sized firms) in strategic research and development (R\&D) firm-choices occurring within small time windows and an evaluation of the extent of the firm's exploratory knowledge activity. In particular, value is co-created in use, because customers assess and determine the value of the proposition on the basis of the specificity of their usage. This paper focuses on the impact that moving between exploitation and exploration can have on a firm's innovative performance. This study develops a conceptual framework of value creation and appropriation in the technological growth process in medium sized multinationals and analyses this in an exploratory longitudinal multi-case study. This research approach is inductive and deductive, which means that the aim is directed towards theory building through the original use of existing theory from both international managerial literature and empirical analysis. Overall, this study provides a unique contribution in terms of both theoretical development and managerial implications by investigating the two activities (operations and R\&D activities) with the aspects of global development.
\end{abstract}

Keywords: value systems, knowledge management, medium sized multinationals

\section{Introduction}

Firms need to take into account the relational context when formulating research and production strategies. Competitor identification occupies a central position in strategic management research (Peteraf \& Bergen, 2003; Wu \& Olk, 2014). Prior studies suggest that firms tend to perceive only target firms with comparable capabilities (Chen, 1996). Moreover, the number of competitors perceived by a firm is positively associated with its strong customer ties. Firstly, strong customer ties provide firms with critical competitive information about the necessary market competencies. Secondly, strong customer ties, which typically involve high levels of trust and mutual forbearance, not only greatly reduce the transaction costs associated with the alliance, but also promote information exchange about competitors.

However, the benefits linked to a particular collaborative relationship are not always fully aligned with individual firm-specific strategic objectives. Thus, although firms need to take into account the "relational strategy" that maximizes the value created in its collaborative relationships (Dyer \& Singh, 1998; Ritala \& Tidström, 2014), they should simultaneously follow their own strategic value appropriation objectives in order

Maria Rosaria Marcone, associate professor, Department of Management, Polytechnic University of Marche, Italy.

Domenico Carminucci, assistant researcher and managing director, Department of Management, Polytechnic University of Marche, Italy.

Correspondence concerning this article should be addressed to Maria Rosaria Marcone, Department of Management, Polytechnic University of Marche, P. le Martelli, 8, 60121, Ancona, Italy. E-mail: m.r.marcone@univpm.it. 
to remain competitive as individual entities (Dyer, Singh, \& Kale, 2008; Möller \& Rajala, 2007). In fact, although both value creation and appropriation (also called "capture") are often mentioned in the research, very few studies address them explicitly and most tend to focus on the value-creation within alliances and networks (Adegbesan \& Higgins, 2011; Pitelis, 2012).

The fragmented nature of innovation literature suggests that there are multiple processes of innovation depending on the "type" of innovation involved. This article explores diverging views on innovation and extends the research regarding innovation systems. Technology is conceptualized as potentially useful knowledge or a value proposition which is both an outcome and a medium of value co-creation and innovation.

This conventional view was based on the understanding of how multiple participants (e.g., firms, customers, and other stakeholders) contribute to value creation as well as innovation. Authors adopt much of the literatures that remain "production-centric" and maintain the attention about those firms that "adopt" innovations. Moreover, considering the role that users have, as important agents in the creation process in driving innovative efforts, authors point to a more interactive and systemic view of innovation.

Thus, this article brings together historically divergent perspectives on innovation-particularly those centered on operational activity development and those centered on market relationships - and investigates the underlying practices and processes that generate new ways to create value.

The remainder of the paper is organized as follows: Section 2 devotes wide room to the individuation of consolidated research fields and those that have been highlighted in international management literature, above all in the last few years, to verify in which sector of managerial studies the present research can be set; in section 3, information is given about the firms where the field study has been carried out: size of the sample, data collected, method of collection, and analysis; section 4 gives the qualitative results of the empirical study; and finally, comments and some suggestions for further research are given.

\section{Theoretical Background and the Development of the Hypotheses}

Knowledge is a key source of competitive advantage that differentiates firms' performance, according to the differences in their knowledge resources, developed in manufacturing and research and development (R\&D) activities. Knowledge assets are systems which can be both human- and technology-based that function to manipulate knowledge resources; knowledge growth processes consist of various configurations of knowledge manipulation conducted by the research oriented works belonging to the productive and R\&D activities (Holsapple \& Wu, 2011).

This paper focuses on the impact that moving between exploitation and exploration can have on a firm's innovative performance. A common perspective is that consistent $R \& D$ investment facilitates innovation. It suggests that such transitions between exploration and exploitation are critical and are observable as significant strategic changes in a firm's choices regarding R\&D investments that occur within relatively small time windows.

One should draw attention to the fact that the propensity of analyzed internationalized medium sized firms (IMSFs) to effectively take advantage of new process technologies and their ability to increase the innovative knowledge possessed co-evolve with co-creating customer relational capabilities. Customer relational capabilities create value, because they increase the possibilities to sense and respond and self-reinforce value cycles of dynamic exchange. In this sense, it has been affirmed that knowledge intensive resource (KIR) is the ability of an enterprise to leverage existing knowledge through continuous learning to create new knowledge. 
Many studies further explained that KIR not only refers to the ability to acquire knowledge and information, but also to the organizational capability of protecting knowledge and information in order to encourage staff to use this ability as a tool to work more efficiently (Tseng, 2014). Chen and Fong (2012) stated that the root of KIR lies in the high-level knowledge-based routines that are usually driven by the learning process that is conducted through knowledge processes. They further elaborated that the firms condition these processes based on their governance mechanisms and history, hence path dependencies are generated. Authors hypothesize that:

H1: The ability to increase the innovative knowledge possessed co-evolve with co-creating customer relational capabilities.

This paper contributes to research about knowledge management by presenting a comprehensive model that captures the relationships between knowledge management practices and knowledge-oriented leadership.

The discussion below explains the relationships between knowledge management initiatives and innovation, going on to cover their links to knowledge-oriented leadership. They consider technological knowledge as a dynamic resource, such as potentially useful knowledge and original recombination of practices with the aim of providing novel solutions for new or existing problems.

Organizational learning is a dynamic process of organization and interpretative-integration of new knowledge demand pull or a process that is pushed by new applications of technology.

Literature regarding the impact of institutional investors on a firm's applied R\&D expenses supports the claim that ownership promotes the most opportune R\&D expenses, thus removing the strategic choices of growth both from managerial myopia and from the myopia of institutional investors (Le, Walters, \& Kroll, 2006; Aghion, Van Reenen, \& Zingales, 2013). In fact, R\&D activities appear at the same time to be both a necessity to acquire an emerged opportunity and a long-term investment, while managers and institutional investors are attentive towards the R\&D earnings goal in the short term.

Correspondingly, top-level managers are increasingly recognizing the need to respond to the entrepreneurial imperatives created by their competitive landscapes. However, managers at all levels of the organization can be instrumental in fostering entrepreneurial activity leading to productive innovation results (Kuratko, Hornsby, \& Bishop, 2005; Hornsby, Kuratko, Shepherd, \& Bott, 2009; Ireland, Covin, \& Kuratko, 2009; Goodale, Kuratko, Hornsby, \& Covin, 2011). Recognizing the role of an organization's broad membership in the perpetuation of innovation, the concept of corporate entrepreneurship-as-strategy represents a concrete entrepreneurial orientation and an entrepreneurial opportunity.

It has recently been suggested that control can produce trust when not denying or eliminating the other agents. However, many studies highlight how controls which restrain the freedom of others may be compatible with trust. Control activities explained by environmental risks rather than relational risks can seemingly restrain the other's freedom of action without a negative impact on trust (Hagedoorn \& Duysters, 2002; Huemer, Boström, \& Felzenstein, 2009). In particular, both formal forms of behavior control, output control, or socialization processes can be regarded as sources of information used to support the initiatives taken, with the aim of taking advantage of business opportunities, even with partner auxiliaries, rather than being used to contrast strategic initiatives abroad (it is even considered to represent an attack/as being offensive). Trust can be viewed as an appropriate mechanism to facilitate the adaptation process. This paper proposes this hypothesis:

H2: It is believed that in medium sized firms, strong entrepreneurship drives choices related to investments towards a non-myopic perspective of creation of value over time. 
The current paper investigates empirically the relation between relatively radical changes (radical for medium sized firms) in strategic R\&D firm-choices occurring within small time windows and an evaluation of the extent of the firm's exploratory knowledge activity. In particular, value is co-created in use, because customers assess and determine the value of the proposition on the basis of the specificity of their usage.

Technological opportunities can provide the firms with a competitive advantage in transforming their products and production processes (Freeman \& Perez, 1998).

Although in the literature, many authors claimed that the amount of investment for a firm's R\&D endeavour can determine the accumulation of its technological competencies which in turn determines its technological opportunities and firm innovation, in the firms from the sample investigated, it is more a case of the capacity to accumulate technological competencies in the areas that are strictly productive (experimenting with new materials: development of phases of the new processes and new original procedures of the industrialisation of orders) than the resources that are invested that increase the competitiveness of medium-sized firms in international business markets.

More precisely, the accumulation of competencies determines the possibility to identify the most opportune industrial applications of the technologies available. Knowledge creation involves developing new knowledge content or replacing existing content in the organization's explicit or tacit knowledge pool. Knowledge management creation activities typically relate to the internal development of knowledge through R\&D. Nevertheless, at the same time organizations create knowledge and learn, they may forget or lose track of their acquired knowledge (Miller, Bierly, \& Daly, 2007; Nonaka \& Takeuchi, 2011). Knowledge management application practices should thus focus on making the integration and application of existing knowledge to manufacturing activities and problem solving easier and more effective for the firm (Grant, 1996; Caloghirou, Kastelli, \& Tsakanikas, 2004; Zack, McKeen, \& Singh, 2009). With this in mind, this paper presents the following hypothesis:

H3: Knowledge management manufacturing creation practices have a positive relationship with the company's innovation performance.

Generally, managers are thought to make ineffective decisions regarding R\&D investments, focusing on short-term earnings instead of concentrating on value creation. The emphasis of this body of literature is that changes in R\&D expenditures are evidence of myopic investment decisions. Firms that minimize or resist opportunities to disrupt the R\&D process are thought to add most value for shareholders of the firms.

Management research notes that stable investments in $R \& D$ enable firms to develop sustainable competitive advantages and that productive $R \& D$ is the result of knowledge accumulation that is based on steady investment over time (Mudambi \& Swift, 2014).

\section{Research Methodology}

\section{Methodology}

As far as the methodology adopted in the development of the research is concerned, authors would like to underline the fact that during the different phases, both inductive and deductive methodologies are used, principally adopting a "positive-interpretative" approach. In contrast to many extant studies of MSFs, both survey and objectively measured data are combined; because the secondary data collected contain both resource-level (input) data and subsequent one-year financial data, a higher level of confidence may be attributable to the findings (Figure 1). 


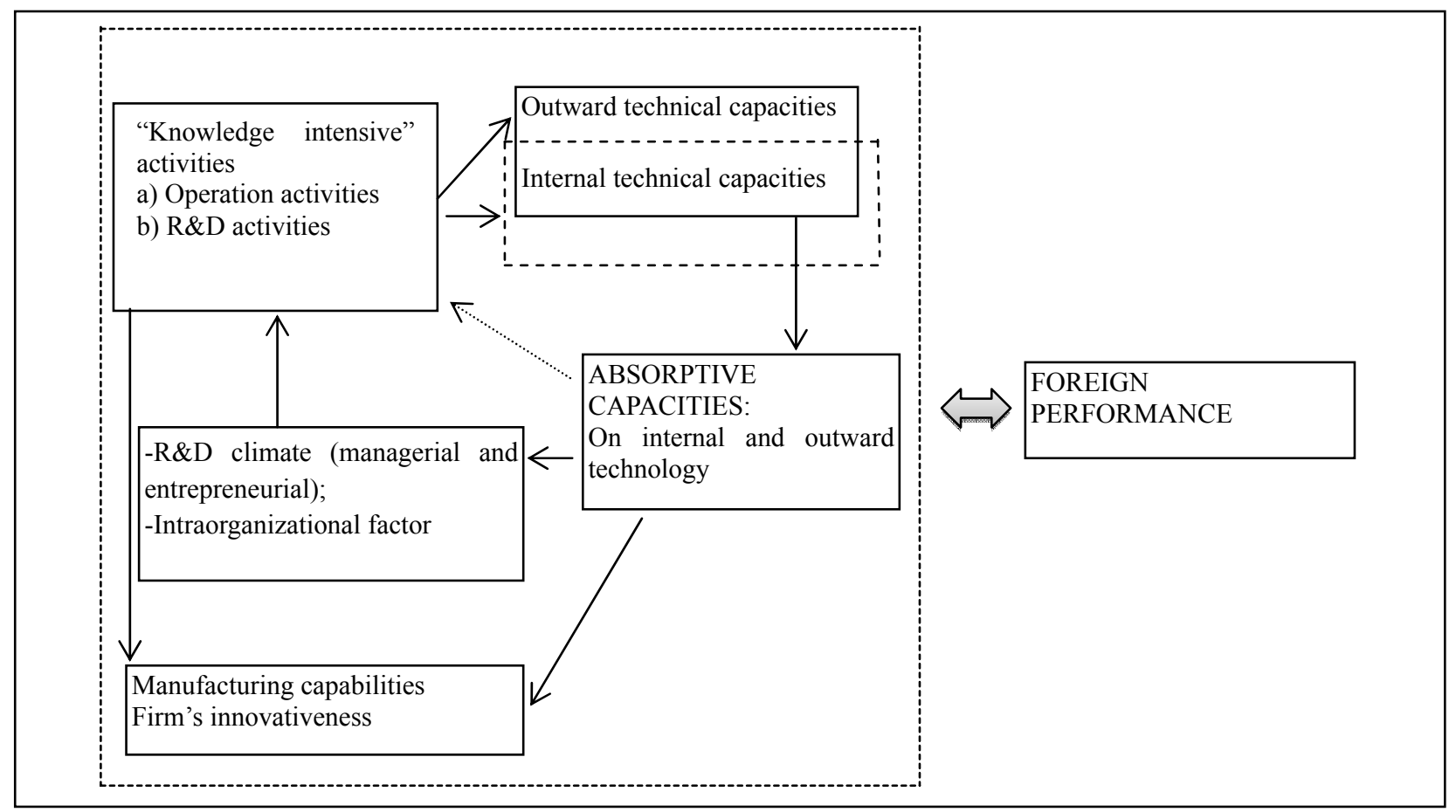

Figure 1. Theoretical framework.

An interpretative, qualitative approach - utilizing selected multi-case study interviews (Yin, 2003; Eisenhardt \& Graebner, 2007) such as the primary data collection method-is chosen, because it helps to navigate and understand the complex issues that are associated with the data quality concept and its relation to the factors involving managerial practices to implement facilities in design and marketing activities. Case studies investigate the issue within a real life context, drawing on the reviews of a number of sources, and provide the means to review theory and practice iteratively. Multiple cases ensure that common patterns are identified rather than generalized from what might change occurrences (Eisenhardt, 1989; Janesick, 2000).

\section{Preliminary Interview Protocol}

Data were collected through 40 semi-structured questionnaires, 45 to 90 min interviews with leaders and participants from all the functional areas involved (marketing and product managers, entrepreneurs, and operational workers) in the process of "design-engineering-production" of each order.

To assess these orientations, authors explicitly asked interviewees about their incentives, goals, internal work in processes, and relationships to other actors and functional areas. Regarding interview protocol, given the nature of the research, the interviewees were not required to stay within the standard questions: An interviewee who seemed to be exploring a fruitful avenue was permitted to continue in that direction. This semi-structured protocol changed over time, as each subsequent interview was used to triangulate the responses from previous interviews and expanded the list of questions as they uncovered more elements of the planning process. This continuous expansion and improvement of the protocol after each interview is a normal part of the process of grounded theory development (Meredith, 1998; Stuart, McCutcheon, Handfield, McLachlin, \& Samson, 2002; Eisenhardt \& Graebner, 2007).

\section{Sample and Data Collection}

The present work highlights the results of this empirical research. The research was carried out during the 
years 2009 to 2014; it involved 30 firms of the sectors of mechanics and electronics located in Central Italy. The firms that belong to the sample were chosen among those that, while having internationalized production and research, maintain and develop the original domestic production site. The sample was chosen taking into consideration IMSFs that progressively invested more resources in R\&D in relation to global investment in the activity of the firm, to understand if the innovation propension has had positive effects both on the total turnover (also this variable has been related to the invested capital) and on the exported turnover. A first basic analysis has been carried out by choosing a graphic method of representation that point out the positioning of firms according to their average tendency to change, with reference to both variables: R\&D/IC (invested capital) vs. turnover/IC and R\&D/IC vs. export/turnover. Elaboration of data regarding the financial and the economic resources invested by the IMSF analyzed in the activity of research and development shows (Figures 2 and 3 ) a good trend in recent years in $\mathrm{R} \& \mathrm{D} / \mathrm{IC}$.

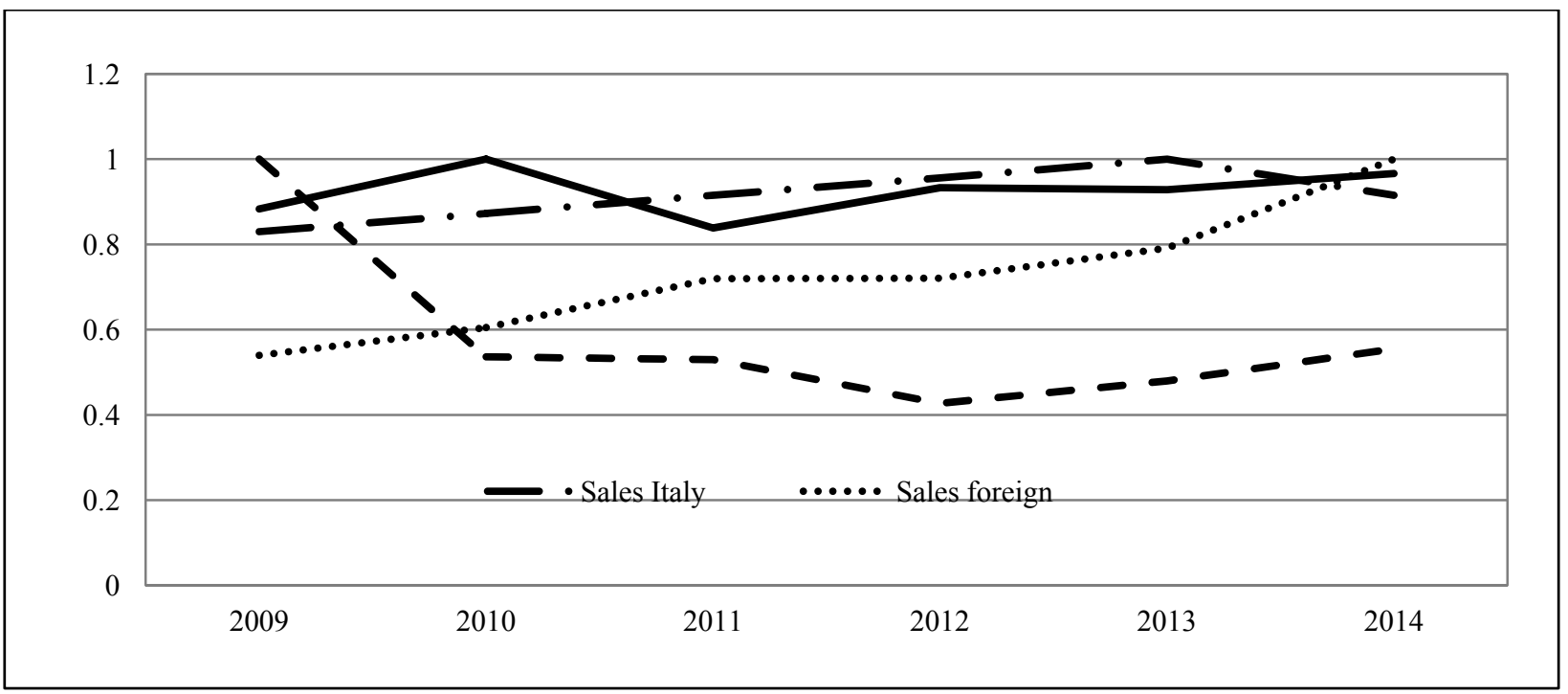

Figure 2. Normalized values. Source: Author's elaboration based on empirical research.

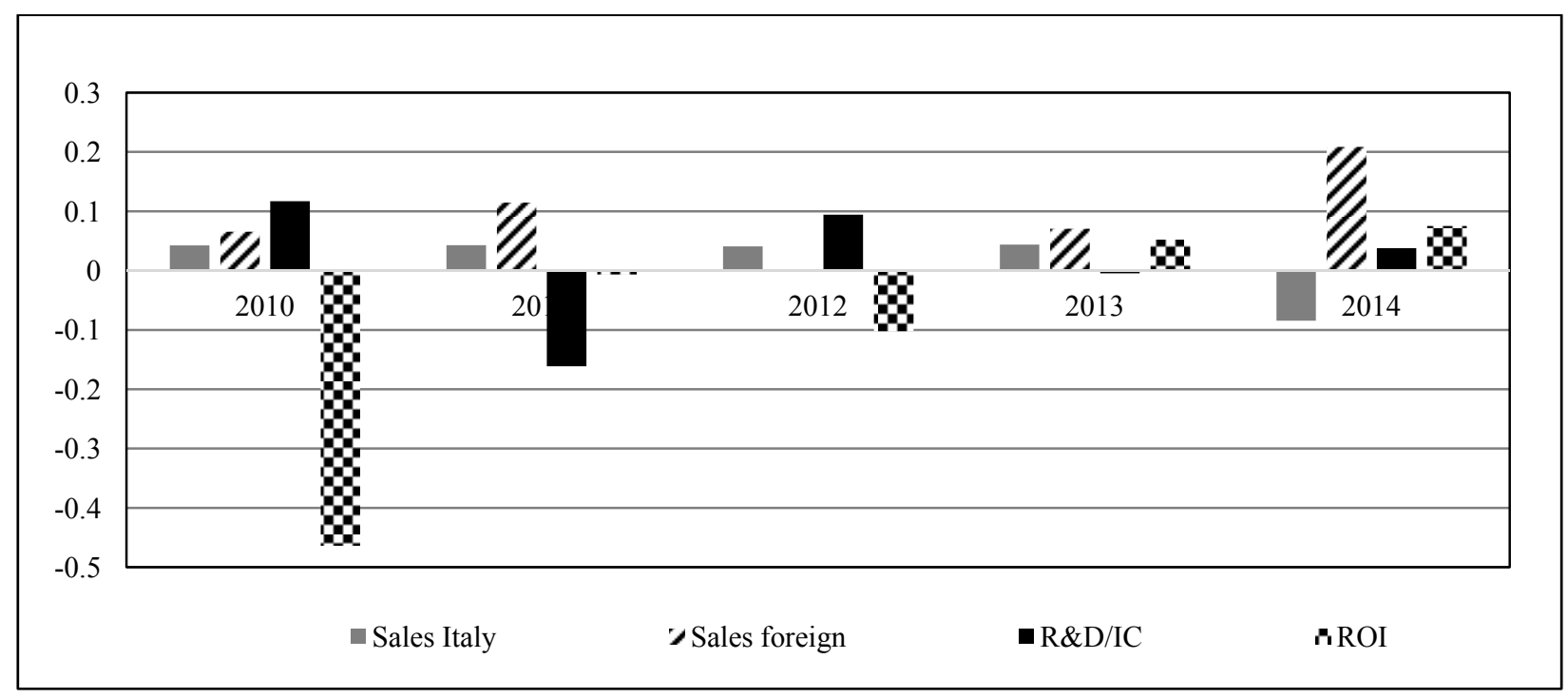

Figure 3. Differential values. Source: Author's elaboration based on empirical research. 


\section{Research Based Production Propensity}

Furthermore, from the point of view of cognitive theory, SMEs face major challenges (Gray, 2006): keeping the firm's capabilities, resources, and routines up to date; maintaining owners' entrepreneurial and managerial competences; acquiring new knowledge; and creating new knowledge and combining it with existing organizational structures and routines. As knowledge-sourcing activities are conducted both internally and externally, firms have to rely both on their combinative capabilities (Kogout \& Zander, 1992) to create new knowledge by recombining their current capabilities and on external networks, that is, on their ability to exploit the breadth and depth of their relationships with other organizations. However, firms' sourcing activities are deeply influenced by their absorptive capacity (ACAP) (Cohen \& Levinthal, 1990; Zahra \& George, 2002; Fabrizio, 2009) both in terms of prior knowledge base and current knowledge acquisition capability. Thus firms that effectively exploit external knowledge to generate innovation can be expected to have a high degree of ACAP.

Recent international business research advocates placing knowledge acquisition and exploitation at the heart of firms' internationalization strategies (Kim \& Atuahene-Gima, 2010; Lisboa, Skarmeas, \& Lages, 2011; McCarthy \& Gordon, 2011; Siren, Kohtamäki, \& Kuckertz, 2012). From this perspective, internationalization is viewed as a learning and knowledge accumulation process. Data from a sample of research-intensive firms of mechanics and electronics using design and engineering activities show that operational-level exploratory and exploitative productive innovation and marketing capabilities allow firms to implement exploratory and exploitative strategies in complex and dynamics international business marketing.

A number of studies suggest that a firm that invests in R\&D activities continuously can foster the firm's innovativeness (Hagedoorn \& Duysters, 2002). As a result, a firm's investment in R\&D activities is an important source for firm innovation.

The firms analyzed engage in research and development to create advantages and increase firm value. However, managing this R\&D process is challenging, as it involves uncertainty both regarding technological trajectories and international business-markets opportunities. Thus, it may be difficult for firms to change their $R \& D$ strategic choices over time, because it is difficult to gather reliable information with which to judge the prospects of their R\&D portfolio.

The acquisition, assimilation, and exploitation of heterogeneous, valuable, knowledge-based resources contribute critically to a firm's competitive advantage and superior performance (Nonaka, 1994; Von Hippel, 2007; Lechner, Frankenberger, \& Floyd, 2010).

A higher level of R\&D capacity improves a firm's ability to exploit sources of knowledge. Much research has treated capability development—changes in stocks of knowledge, operational skills, improvement in production processes, improvement in utilizing raw material, etc.—as a "gap-closing process" (Rockart \& Dutt, 2015).

Firms typically exploit and refine their knowledge by searching in the vicinity of their existing knowledge domains (Levinthal \& March, 1993; Miller, 2002). At the same time, they are under pressure to change their knowledge bases to keep pace with the external technological environment and to compensate for the exhaustion of recombinant opportunities in existing domains (Fleming, 2001; Kim \& Kogut, 1996).

Technological innovation is the combinatorial evolution of useful knowledge, which is enabled and constrained by existing operational resources and a recombination of overlapping processes with users, technological providers, components providers, and in some cases institutions. 
Knowledge management in this study is analyzed as a set of activities, initiatives, and strategies that companies use to generate and apply knowledge for the improvement of productive and competitive performances.

Authors would like to highlight that the effect of firm innovativeness on business performance is relevant in a competitive context that is characterized by market turbulence and competitive intensity.

The support and the experience of "expatriate entrepreneur" (a member or owner family nucleus) senior management in entrepreneurial activities in subsidiaries are more and more important in creating and stimulating the organizational environment for new business ideas and practices. Naturally, the relationship between entrepreneurial orientation and the development of capabilities requires the constant rebuilding of businesses and processes in a continuous and emerging manner.

In line with previous literature, results show that although knowledge management practices themselves are important for innovation purposes, the existence of this kind of leadership encourages the development and use of knowledge management exploration (i.e., creation) and exploitation (i.e., storage, transfer, and application) practices (Nguyen \& Mohamed, 2011; Von Krogh, Nonka, \& Rechsteiner, 2012). Entrepreneurial leadership behavior is an important factor, since leaders have an enormous impact on the direction and effectiveness of knowledge management within the firm's organizations.

Traditionally, scholars consider organizational size to be an important predictor of innovation adoption. Although most medium enterprises suffer from the lack of the necessary means and know-how to invest in innovation, they boast a major advantage with respect to the larger firms: Their size gives them more flexibility and independence from institutional bureaucracy. This structure can promote an innovative spirit and can foster innovation (De Jong \& Marsili, 2006; Laforet, 2008).

In general, the way a manufacturing plant utilizes its existing knowledge through knowledge management practices determines this knowledge's utility in innovation. Performance includes multiple dimensions. Studies in strategic management focus most commonly on firms' financial performance (Chen, Delmas, \& Lieberman, 2015). Although the current research approach treats storage as a knowledge-exploitation process, this study considers the link with results in innovation to be indirect. Specifically, knowledge dissemination and application emerge as two characteristic components of knowledge management with major potential for the generation of sustainable competitive advantages based on innovation, due to their complexity, ambiguity, and uniqueness to the firm.

\section{Conclusions}

On site verification of some research hypotheses and the re-elaboration of balance sheet data allow one to attain some partial results in this field of research that is still prevalently in its exploratory stages.

The current paper investigates empirically the relation between relatively radical changes (radical for medium sized firms) in strategic R\&D firm-choices occurring within small time windows and an evaluation of the extent of the firm's exploratory knowledge activity. This paper presents empirical evidence of the mediating effect of knowledge management practices in the relationship between knowledge-oriented leadership and innovation performance.

Therefore, a higher R\&D investment can result in higher innovativeness for the firm. Prior studies find that R\&D investment has a positive relationship with a firm's innovativeness. For instance, authors asserted that internal R\&D reveals the opportunity for a firm's dynamic improvement and innovation. 
The results suggest that firm innovativeness is critical for firms that seek to enhance business performance in highly turbulent and highly competitive markets: Firms must continually innovate to ensure that their productive plants are aligned with rapidly changing use in international business markets with intensely competitive landscapes. To ensure that their firms prosper under such difficult market conditions, managers should nurture a culture of high innovativeness that "encourages, supports, and rewards breakthrough thinking".

The overlap in the knowledge base between users and the analyzed firms during the development (engineering) of such orders leads to "order development organizations" possessing an increased capacity to influence users' priorities.

In the current economic and competitive context, one can see that the competitive advantage (and specialization) of Italian research based firms, in the international context, is based on the ability to perform, at a cost that is still today-competitive the complete cycle of "design-engineering-production". In this sense, the creation of value is the core purpose and central process of economic exchange.

They found also that the relative additional information gained through strong customer ties is likely to be greater for firms with a technological advantage than for firms who do not possess such an advantage. This situation may shield a firm's attention to potential competitors that currently do not possess comparable technological capabilities. This is particularly critical if on site verification of some research hypotheses and the re-elaboration of balance sheet data allow one to attain some partial results in this field of research that is still prevalently in its exploratory stages.

Although value appropriation eventually takes place on the firm level (i.e., it shows on the bottom line), the processes leading to it may be firm-related. For instance, competing firms tend to form alliances or "owner firm groups" that compete against other coalitions. Thus, various "coopetitive forms" may be competing for the appropriated value. Analyses of coopetition should therefore take into account the competitive element insofar as it affects value appropriation either directly (direct coopetition for the created value) or indirectly (the potential for future coopetition). These divergent value-appropriation objectives between firms and "coopetitive forms" do not reduce the amount of value available to an individual actor and may also cause more virtuous forms of growth.

Authors suggested that both value creation and value appropriation are affected by relational and firm-level strategies in various ways. They also posited that the interplay of these concepts is dynamic in that they may vary and evolve over time within different "technological coopetitive strategies" ("owner relationships" and "non-owner relationships"), which affects the evolution of value creation and appropriation. This form of temporal dynamics is visible in many of the analysed cases.

\section{References}

Adegbesan, J. A., \& Higgins, M. J. (2011). The intra-alliance division of value created through collaboration. Strategic Management Journal, 32(2), 187-211.

Aghion, P., Van Reenen, J., \& Zingales, L. (2013). Innovation and institutional ownership. American Economic Review, 103(1), $277-304$.

Caloghirou, Y., Kastelli, I., \& Tsakanikas, A. (2004). Internal capabilities and external knowledge sources: Complements or substitutes for innovative performance. Technovation, 24, 29-39.

Chen, C. M., Delmas, M. A., \& Lieberman, M. B. (2015). Production frontier methodologies and efficiency as a performance measure in strategic management research. Strategic Management Journal, 36(1), 19-36.

Chen, L., \& Fong, P. S. W. (2012). Revealing performance heterogeneity through knowledge management maturity evaluation: A capability-based approach. Expert System Applications, 39(18), 13523-13539. 
Chen, M. J. (1996). Competitor analysis and interfirm rivalry: Toward a theoretical integration. Academy of Management Review, $21(1), 100-134$.

Cohen, W. M., \& Levinthal, D. A. (1990). Absorptive capacity: A new perspective on learning an innovation. Administrative Science Quarterly, 35(1), 128-152.

De Jong, P. J. J., \& Marsili, O. (2006). The fruit flies of innovations: A taxonomy of innovative small firms. Research Policy, 35(2), 213-229.

Dyer, J. H., \& Singh, H. (1998). The relational view: Cooperative strategy and sources of interorganizational competitive advantage. Academy of Management Review, 23(4), 660-679.

Dyer, J. H., Singh, H., \& Kale, P. (2008). Splitting the pie: Rent distribution in alliances and networks. Managerial and Decision Economics, 29(2-3), 137-148.

Eisenhardt, K. M. (1989). Building theories from case study research. Academy of Management Review, 14(4), 532-550.

Eisenhardt, K. M., \& Graebner, M. E. (2007). Theory building from cases. Academy of Management Journal, 50(1), $25-32$.

Fabrizio, K. R. (2009). Absorptive capacity and the search for innovation. Research Policy, 38(2), 255-267.

Fleming, L. (2001). Recombinant uncertainty in technological search. Management Science, 47(1), 117-132.

Freeman, C., \& Perez, C. (1998). Structural crises of adjustment: Business cycles and investment behavior. In G. Dosi, C. Freeman, and R. Nelson (Eds.), Technical change and economic theory. London: Pinter Publishers.

Goodale, J. C., Kuratko, D. F., Hornsby, J. S., \& Covin, J. G. (2011). Operations management and corporate entrepreneurship: The moderating effect of operations control on the antecedents of corporate entrepreneurial activity in relation to innovation performance. Journal of Operations Management, 29(1), 116-127.

Grant, R. M. (1996). Toward a knowledge based theory of the firm. Strategic Management Journal, 17, 109-122.

Gray, C. (2006). Absorptive capacity, knowledge management and innovation in entrepreneurial small firms. International Journal of Entrepreneurial Behaviour \& Research, 12(6), 345-360.

Hagedoorn, J., \& Duysters, G. (2002). Learning in dynamic inter-firm networks: The efficacy of multiple contacts. Organization Studies, 23(4), 525-548.

Holsapple, C. W., \& Wu, J. (2011). An elusive antecedent of superior firm performance: The knowledge management factor. Decision Support System, 52(1), 271-283.

Hornsby, J. S., Kuratko, D. F., Shepherd, D. A., \& Bott, J. P. (2009). Manager's corporate entrepreneurial actions: Examining perception and position. Journal of Business Venturing, 24(3), 236-247.

Huemer, L., Boström, G. O., \& Felzenstein, C. (2009). Control-trust interplays and the influence paradox: A comparative study of MNC-subsidiary relationships. Industrial Marketing Management, 38(5), 520-528.

Ireland, R. D., Covin, J. G., \& Kuratko, D. F. (2009). Conceptualizing corporate entrepreneurship strategy. Entrepreneurship Theory and Practice, 33(1), 19-46.

Janesick, V. (2000). The choreography of qualitative research design. In Y. S. Lincoln (Ed.), Handbook of qualitative research (pp. 379-399). California: Sage Publications.

Kim, D. J., \& Kogut, B. (1996). Technological platforms and diversification. Organization Science, 7(3), 283-301.

Kim, N., \& Atuahene-Gima, K. (2010). Using exploratory and exploitative market learning for new product development. Journal of Product Innovation Management, 27(4), 519-536.

Kogout, B., \& Zander, U. (1992). Knowledge of the firm, combinative capabilities and the replication of technology. Organization Science, 3(3), 383-397.

Kuratko, D. F., Hornsby, J. S., \& Bishop, J. W. (2005). An examination of managers' entrepreneurial actions and job satisfaction. International Entrepreneurship and Management Journal, 1(3), 275-291.

Laforet, S. (2008). Size, strategic, and market orientation effects on innovation. Journal of Business Research, 61(7), $753-764$.

Le, S. A., Walters, B., \& Kroll, M. (2006). The moderating effects of external monitors on the relationship between R\&D spending and firm performance. Journal of Business Research, 59(2), 278-287.

Lechner, C., Frankenberger, K., \& Floyd, S. W. (2010). Task contingencies in the curvilinear relationships between intergroup networks and initiative performance. Academy of Management Journal, 53(4), 865-889.

Levinthal, D. A., \& March, J. G. (1993). The myopia of learning. Strategic Management Journal, 14(S2), 95-112.

Lisboa, A., Skarmeas, D., \& Lages, C. (2011). Entrepreneurial orientation, exploitative and explorative capabilities, and performance outcomes in export markets: A resource based approach. Industrial Marketing Management, 40(8), 1274-1284.

McCarthy, I. P., \& Gordon, B. R. (2011). Achieving contextual ambidexterity in R\&D organizations: A management control system approach. R\&D Management, 41(3), 240-258. 
Meredith, J. R. (1998). Building operations management theory through case and field research. Journal of Operations Management, 16(4), 439-452.

Miller, B., Bierly, P., \& Daly, P. (2007). The knowledge strategy orientation scale: Individual perceptions of firm-level phenomena. Journal of Managerial Issues, 19(3), 414-435.

Miller, K. D. (2002). Knowledge inventory and managerial myopia. Strategic Management Journal, 23(8), 689-706.

Möller, K., \& Rajala, A. (2007). Rise of strategic nets-New modes of value creation. Industrial Marketing Management, 36(7), 895-908.

Mudambi, R., \& Swift, T. (2014). Knowing when to leap: Transitioning between exploitative and explorative R\&D. Strategic Management Journal, 35(1), 126-145.

Nguyen, H. N., \& Mohamed, S. (2011). Leadership behaviors, organizational culture and knowledge management practices: An empirical investigation. Journal of Management Development, 30(2), 206-221.

Nonaka, I. (1994). A dynamic theory of organizational knowledge creation. Organization Science, 5(1), 14-37.

Nonaka, I., \& Takeuchi, H. (2011). The wise leader. Harvard Business Review, 89(5), 58-67.

Peteraf, M. A., \& Bergen, M. (2003). Scanning dynamic competitive landscape: A market based and resource based framework. Strategic Management Journal, 24(10), 1027-1041.

Pitelis, C. (2012). Clusters, entrepreneurial ecosystem co-creation, and appropriability: A conceptual framework. Industrial and Corporate Change, 21(6), 1359-1388.

Ritala, P., \& Tidström, A. (2014). Untangling the value-creation and value-appropriation elements of coopetition strategy: A longitudinal analysis on the firm and relational levels. Scandinavian Journal of Management, 30(4), 498-515.

Rockart, S. F., \& Dutt, N. (2015). The rate and potential of capability development trajectories. Strategic Management Journal, $36(1), 53-75$.

Siren, C. A., Kohtamäki, M., \& Kuckertz, A. (2012). Exploration and exploitation strategies, profit performance, and the mediating role of strategic learning: Escaping the exploitation trap. Strategic Entrepreneurship Journal, 6(1), 18-41.

Stuart, I., McCutcheon, D., Handfield, R., McLachlin, R., \& Samson, D. (2002). Effective case research in operations management: A process perspective. Journal of Operations Management, 20(5), 419-433.

Tseng, S. M. (2014). The impact of knowledge management capabilities and supplier relationship management on corporate performance. International Journal of Production Economics, 154, 39-47.

Von Hippel, E. (2007). Horizontal innovation network-by and for users. Industrial and Corporate Change, 16(2), 293-315.

Von Krogh, G., Nonaka, I., \& Rechsteiner, L. (2012). Leadership in organizational knowledge creation. A review and framework. Journal of Management Studies, 49(1), 240-277.

Wu, J., \& Olk, P. (2014). Technological advantage, alliances with customers, local knowledge and competitor identification. Journal of Business Research, 67(10), 2106-2114.

Yin, R. (2003). Case study research: Design and methods (3rd ed.). Thousand Oaks: Sage.

Zack, M., McKeen, J., \& Singh, S. (2009). Knowledge management and organizational performance: An exploratory survey. Journal of Knowledge Management, 13(6), 392-409.

Zahra, S. A., \& George, G. (2002). Absorptive capacity: A review, reconceptualization, and extension. Academy of Management Review, 27(2), 185-203. 